\title{
The Feasibility of using Supplementary Materials to Foster Students' Critical Reading Ability in Chinese Extensive Reading Classes
}

\author{
Gao Qing, Ma Xiao
}

School of Foreign Languages and Literature, Wuhan University, China

\begin{abstract}
The importance and benefits of critical reading (CR) in the study of English as a Foreign Language (EFL) are often emphasized by scholars, particularly in relation to extensive reading (ER). However, some related studies show that the Chinese ER textbooks do not pay much attention to CR, which indicates that students lack sufficient materials to foster their CR ability. Combining these aspects, this research aims to find the feasibility of using supplementary materials to foster CR ability in Chinese ER classes.
\end{abstract}

Keywords - Supplementary Materials, critical reading, extensive reading.

\section{INTRODUCTION}

Critical reading (CR), a type of reading that requires readers to have an active engagement in thinking deeply by applying various skills, is proved to improve students' academic performance and arouse their social consciousness as well. Considering this, some people argued that it could be appropriate to be taught in ER classes, since ER involves both language study and real-world experiences. However, some scholars indicate that Chinese students do not have ample reading materials, while there are little published textbooks having made efforts on improving students' CR ability. All of these suggest that ER teaching materials for CR education could be improved in some ways. From this aspect, it is reasonable to argue that supplementary materials for textbooks should be introduced in ER classes to develop students' CR ability. Therefore, this research aims to study the feasibility of the use of supplementary materials for cultivating students' CR ability in ER classes, and the research question is what effects of supplementary reading have on students' CR skills in ER classes.

\section{LITERATURE REVIEW}

\subsection{The definition of critical reading (CR)}

CR first emerged from western countries and many scholars have given a definition of it. Twining and Pirozzi emphasize CR's usage in establishing the purpose of the writer. According to Twining (Twining, 1985: 322), the initial concerns of $\mathrm{CR}$ are who wrote the article, what are the author's qualifications, and (what seems to be) the purpose of publication. Likewise, Pirozzi also points out (Pirozzi, 2003: 325) that CR represents the high-level comprehension of the written material which requires readers to recognize the writer's purpose. In addition, Pirozzi further indicates that CR needs interpretation and evaluation skills that enable readers to find the important information and separate facts from opinions, which means CR needs readers to accurately understand a text and identify true information within it. Therefore, it is easy to conclude that $\mathrm{CR}$ is a reading process that requires readers to understand the aim of a piece of writing and to judge and access what they have read, rather than simply reading and accepting the writer's opinion. 


\subsection{Critical reading in China}

Chinese students sometimes tend to be regarded as lacking critical reading abilities (Huang, 2010). However, actually, nowadays critical reading has aroused increasing attention in China. Current educational reform in China indicates that both policy makers and scholars have great concerns regarding this problem (Jiang, 2013). To be more specific, on the one hand, in 2010, Chinese Ministry of Education released the National Medium and Long-Term Educational Reform and Development Plan of 2010 to 2020 , in which it points out that improving quality is the core task for the development of higher education, and the basic aim of college English teaching is to train students to have the ability to read text. Also, what needs to be noted is that the developmental aim of education requires students to comprehensively and comparatively analyze different information and be able to draw their own conclusions in the end. This is consistence with the definition of $\mathrm{CR}$, that is, to read the text and give your own judgement. On the other hand, Wang searched the China National Knowledge Infrastructure website and counted the literature related to critical reading; the result indicated that there is an increasing amount of literature concerning the critical reading, especially in the past 5 years (Wang, 2018). Meanwhile, the Chinese citizen's scientific quality benchmark mentions that citizens should have information literacy, which includes that people should be capable to integrate new information into existing knowledge with the ability to organize the information gained through preliminary processing. Based on this, Cai (2020) further indicates that this ability should be equipped with, especially by students majoring in English. For the reason that after graduating, most of them would become the output of information, such as scientific research papers, foreign trade finance reports, writer's novels, speeches by agency spokesmen, media reports, etc. It means that when they get the first-hand information, they need to process it before publishing to the public. And the reliability of the information they generate or disseminate directly relates to the inputs below the vast number of recipients and forwarders. This indicates that English majors should be able to read critically so that they could put forward to their own understanding of the text. All of these means that much attention has been given on $\mathrm{CR}$ from both government level and educators.

To meet the needs of CR teaching, ER materials should be equipped with the following principles.

1. The reading materials should be comprehensible, and students should know about $98 \%$ (or more) of the words in the reading passages ideally (Hu \& Nation, 2000), while CR is the highest level of reading, which require readers to make proper evaluations of what they have read. Therefore, understanding the text is the base of CR.

2. Texts in coursebooks should be cognitively and affectively engaging (Tomlinson, 2012: 164). One of the aims of CR is to understand the text and assess what they have read. If the text is unappealing, students may lose interest of reading it, let alone to assess the text.

3. Texts in coursebooks should be related to the students' personal lives so that they could make the connections with the text and their lives. The reason of this is that if the text could remind students of personal meaning, which is directly associated with their own life, they could locate themselves in broader social issues and their voice could be enriched (Heffernan \& Lewison, 2003; 2005, Kamler, 1999). Also, CR is an activity that incorporates the reader's personal thinking alongside the textual information. If the text is far away from students' life, could not improve the possibility of deep processing and CR ability.

4. Texts should be written by both native and non-native speakers of English (Hu \& Mckay, 2014). As the trend of ELF (English as a lingua franca) is prevailing, students should have the ability to cope with texts written by people all over the world, instead of being just written by native speakers.

However, ER coursebooks in China seems to have not met the demands of CR teaching, especially for ER coursebooks. Renandya, Hu and Xiang choose 8 extensive 
reading coursebooks in use in China, all of which are designed for undergraduates and published by highly reputable publishers or edited by well-known scholars. They examine them from 9 aspects with 3 aspects being consistent with the standard mentioned above (Principle 1, $2,4)$. However, the results showed that the average score of those 3 principles are $1.625,1.5$ and 1.125 respectively, which is higher than little reflecting and lower than somewhat reflecting (Scores are given by 3 levels, $1=$ litter, 2=somewhat, 3=much) (Renandya, Hu \& Xiang, 2015). Thus, it seems that, in China, there are few published textbooks that make efforts to improve students' critical reading ability. Considering this, this research is intended to fill the gap between the needs of CR ability and the inadequate inputs of $\mathrm{CR}$ in Chinese textbook through supplementary materials.

\section{RESEARCH DESIGN}

Subjects investigated are taken from one ER teacher and 74 sophomores in two classes majoring in English in a Chinese college (coded as "college X"). The analysis of results from their last ER examination indicates that their levels of English ability are relatively equal. The teacher was selected owing to her experienced, who has already taught reading for over 10 years with the focus on ER for 5 years. Consent forms were sent to all participants along with information on the aims and benefits of this research, their right to withdraw from the research, and what kind of data would be used. No objections were raised and all participants signed the consent form.

The textbook they used is named Reading to Develop Your Ideas, which is also analyzed by Renandya's team and gets the highest scores in all of those 8 textbooks. However, it still has some problems. For example, all of texts are situated in USA and written by native speakers of English (Renandya, Hu \& Xiang, 2015). Although some articles are intriguing, they are a little bit far away from Chinese students' life, which means students might have difficulties to have deep thinking and develop their CR ability. The chosen article of the textbook is entitled "A Crime Of Compassion", the central theme of which is euthanasia. The ethical implications immediately engage the reader as the writer tells a true experience of a doctor who allows a patient to die after witnessing intolerable pain and suffering as a result of disease. Subsequently, the doctor is accused of murder by a TV audience.

There are 3 articles being chosen as supplementary materials. Article one raised some questions of physician assisted dying written by non-native English speaker; article 2 is a foreign event about a dying man who is believed to take advantage of euthanasia; and article 3 talks about a Chinese real event of euthanasia, which is connected with Chinese students. All of those articles are comprehensible.

\subsection{Research procedures}

This quasi-experiment contains two classes of students majoring in English; one controlled group and one experimental group. This allows the researcher to test a single variable to test the hypothesis by looking for changes brought on by alterations to the variable, which meets the requirement of research question, aiming to find out whether supplementary materials are useful or not. In this research, the teacher will use the same article as the teaching material for both classes. And the only difference is the supplementary reading materials, in the control group, they used their textbook as usual without supporting materials, while the experimental group was provided with supplementary materials which were given before the class and referred to during the teaching process.

The quantitative data was collected in the form of written assignments, which requires students in both classes to give their opinions on euthanasia with reasons to support their argument after taking the class.

\subsection{Approach to data analysis}

Before giving results of this study, it is necessary to introduce approaches for interpreting data. 74 students participated in this research, and 66 of them will be considered for data analysis. 8 responses were discounted due to plagiarism or the withdrawal of a written response. A total of 66 data sets will be used to examine the relationship between supplementary materials and $\mathrm{CR}$ ability in students. The writing analysis will be divided into 4 aspects:

1) the correlation of students' willingness to express 
with the use of supplementary materials.

2) the correlation of students' stance with the use of supplementary materials.

3) the correlation of students' self-experience with the usage of supplementary materials.

4) the correlation of social awareness raised from students' writing with the usage of supplementary materials.

The writing assignment is mandatory for every student in both the control and variable groups resulting in a large number of data for analysis. The comparison between the two classes will present the impact of supplementary materials from above-mentioned four aspects, and charts and diagrams will be presented to support this.

\section{RESULTS}

English proficiency has been improved for most students in experimental group compared with those in controlled group, as it can be seen in Table 4.1.
Table 4. 1 Average grade in controlled group and experimental group

\begin{tabular}{|l|l|l|}
\hline Group & $\begin{array}{l}\text { Controlled } \\
\text { group }\end{array}$ & $\begin{array}{l}\text { Experimental } \\
\text { group }\end{array}$ \\
\hline $\begin{array}{l}\text { Average grade } \\
\text { (Total 100) }\end{array}$ & 81.2 & 83.6 \\
\hline
\end{tabular}

The reasons of it could be concluded and listed below briefly, which would be given detailed explanations in the following part.

1. Students were more willing to express themselves.

2. Students were more neutral to comprehend the article.

3. Students were more subjective to read the world through making connection with themselves.

4. Students were more objective to read the world through social awareness improvement.

\subsection{Willingness to express one's self}

Chart 4.1: The number of written words in the controlled and experimental class

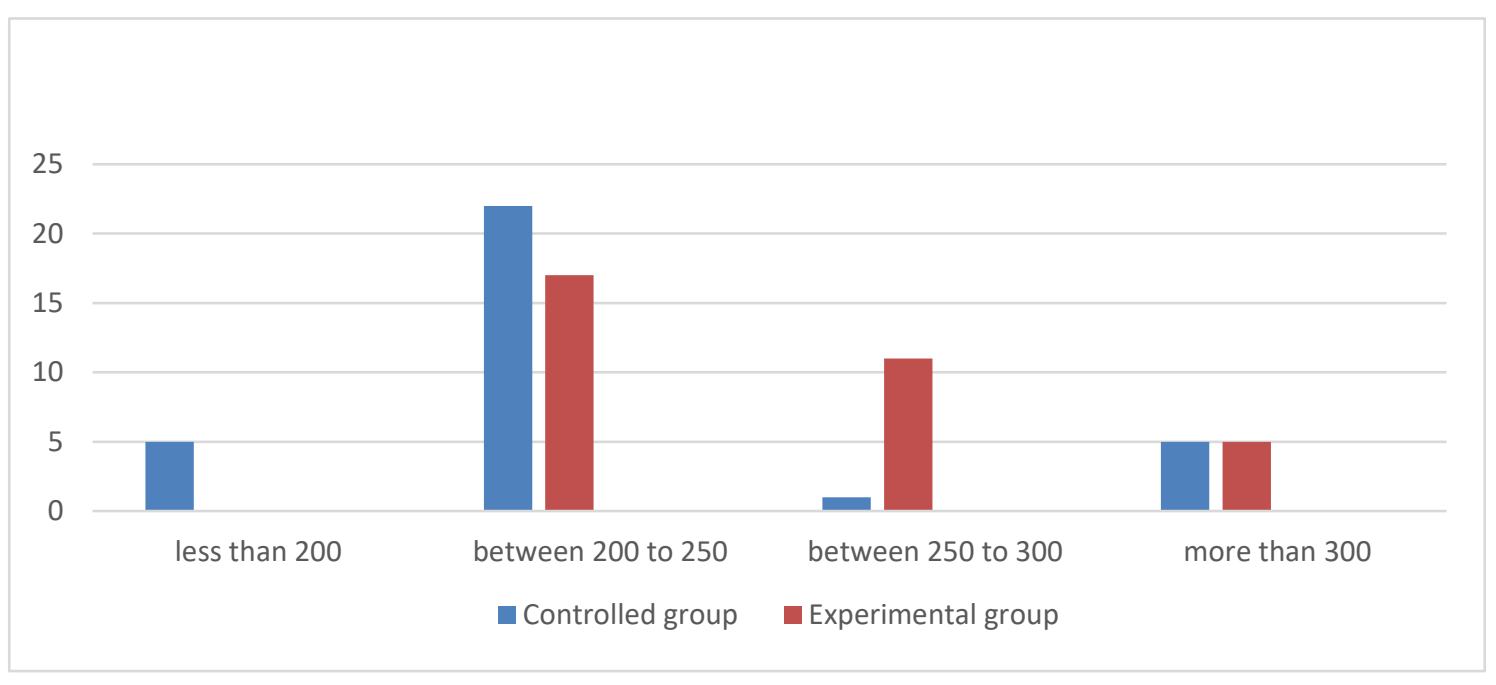

Chart 4.1 makes a comparison between two classes, which could indicate that students are more willing to express themselves with the support of supplementary materials (the willingness for expressing is only based on the word count in this research). Participants were required to submit no fewer than 200 words, and they have one week to finish it. The result shows that 5 of the control group failed to meet this requirement, while the experimental group had a higher proportion of respondents who submitted over 250 words and 2 produced over 600 words within the same assignment. In short, those in the experimental group tend to write more words, indicating that supplementary materials may have contributed to students' willingness to express. 


\subsection{Increasing neutrality}

Chart 4.2: Student stance on euthanasia in the controlled and experimental class (do you agree/disagree with Euthanasia?)

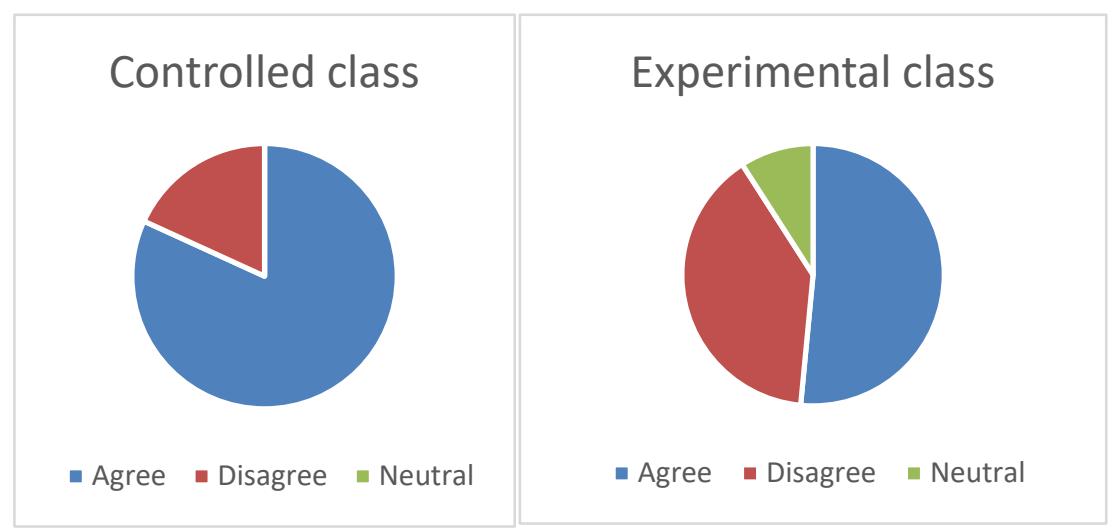

Findings from students' writing assignments, it is easy to note that those in the experimental group have more diverse views on euthanasia. In the controlled group, about $80 \%$ of students agree with euthanasia, while in the experimental class this figure is much lower where $55 \%$ students are in favor of euthanasia, $10 \%$ hold a neutral stance and $35 \%$ hold a view directly opposed to the writer of the passage in textbook. The writer of the article in the textbook is in support of euthanasia and we can clearly see in the Chart 4.2 that the majority of participants in the control group aligned with this position. This stands in contrast to the experimental group who had access to supplementary materials. With these reading materials, students were able consider this evocative issue from different positions and develop their own views on the topic rather than simply agreeing with the writer of the original article. Therefore, it could be concluded that students with supplementary materials are better equipped to consider multi-lateral views of a topic rather than being entrenched in one-sided support.

\subsection{Increased subjectivity for making connections of personal life}

Table 4.2: References to personal experience

\begin{tabular}{|c|c|}
\hline Class & $\begin{array}{c}\text { Support showing to the personal } \\
\text { connections with the issue } \\
\text { (number of writings) }\end{array}$ \\
\hline Controlled class & 2 \\
\hline Experimental class & 9 \\
\hline
\end{tabular}

Table 4.3: Examples of references to personal life (experimental student)

\begin{tabular}{|l|l|}
\hline \multicolumn{1}{|c|}{ Life experience } & \multicolumn{1}{|c|}{ Living surroundings } \\
\hline $\begin{array}{l}\text { I can well remember } \\
\text { that there was a present, China's legal } \\
\text { time when I was in } \\
\text { primary school, my } \\
\text { mother was badly }\end{array}$ & $\begin{array}{l}\text { mechanism and government } \\
\text { not perfect, the medical } \\
\text { surt....... }\end{array}$ \\
\hline \multirow{2}{*}{ sackward. system is also } \\
& $\begin{array}{l}\text { The National people's } \\
\text { Representative proposes to } \\
\text { include euthanasia in the } \\
\text { compilation of personality } \\
\text { rights in the Civil Code. }\end{array}$ \\
\hline
\end{tabular}

When presented with supplementary reading material, it was found that participants were more likely to refer to their personal life, including experience and their environments. 


\subsection{Increased objectivity for making connections with} social justice

Chart 4.3: Writing of social justice awareness

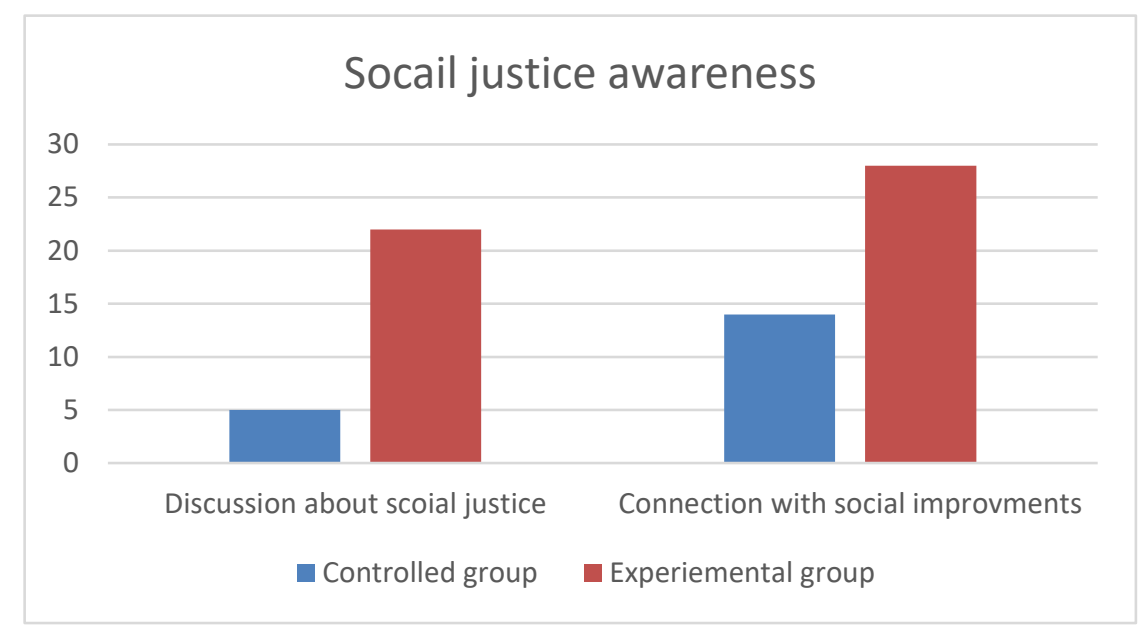

\subsubsection{Discussion about social justice}

As shown in the chart 4.3, there are clear differences between the two groups when it comes to social justice (in relation to the text), which indicates that supplementary materials may offer readers more possibilities to consider different understandings of euthanasia. For example, the text mentioned that the right to choose mercy-killing/euthanasia is not equal for all the citizens; some students were able to discuss social justice from this aspect and mentioned that not all social classes can afford the economic cost of mercy-killing.

\subsubsection{Connections with social improvements}

As shown in chart 4.3 (above), more than one third of students in the experimental group were conscious of social realities/issues, while less than one fifth of those in the control group displayed the same awareness. Almost none of controlled students mentioned medical progress without the teacher's input, giving no further explanation, discussing the point at only a superficial level, as indicated in table 4.4:

Table 4.4: Comparison of the depth of discussion

\begin{tabular}{|l|l|l|}
\hline $\begin{array}{l}\text { Controlled } \\
\text { group }\end{array}$ & Experimental group & $\begin{array}{l}\text { Controlled } \\
\text { group }\end{array}$ \\
\hline $\begin{array}{l}\text { Euthanasia can } \\
\text { save the limited } \\
\text { social medical }\end{array}$ & $\begin{array}{l}\text { legalization } \\
\text { euthanasia is the of }\end{array}$ & $\begin{array}{l}\text { Euthanasia can } \\
\text { save the limited } \\
\text { social medical }\end{array}$ \\
\hline
\end{tabular}

\begin{tabular}{|c|c|c|}
\hline $\begin{array}{l}\text { resources and } \\
\text { redistribute the } \\
\text { social medical } \\
\text { resources. }\end{array}$ & $\begin{array}{l}\text { basic requirement of } \\
\text { the society ruled by } \\
\text { law, and it is a } \\
\text { significant progress } \\
\text { of the social concept } \\
\text { of life and death. It } \\
\text { can also promote the } \\
\text { construction of } \\
\text { modern civilization } \\
\text { and morality. }\end{array}$ & $\begin{array}{l}\text { resources and } \\
\text { redistribute the } \\
\text { social medical } \\
\text { resources. }\end{array}$ \\
\hline
\end{tabular}

From what has been discussed, it is possible to conclude that supplementary materials could have positive impacts on students' CR ability, from which students are not only making connections with their daily life, but they are also able to expand their vision to society as a whole and begin to investigate what could be improved to make the world better.

\section{DISCUSSION}

This research indicates the feasibility of using supplementary materials to foster students CR ability for Chinese students in ER classes, since most all students in the experimental group could be seen some improvement in their CR ability, which could be explained from the following aspects. 


\subsection{Willingness to express}

Although some people may argue that language ability should not be defined by how many words students write, the quality of writing is more significant in evaluating their language proficiency level. This study prefers to view word count as a direct and visual indicator for willingness to express (Zhang, 2016). In China, the TEM-4 scoring rubric (Test for English Majors-4), which is typically designed for college students in the second grade, requests that candidates should write more than 200 word and point outs that they will lose scores if they do not meet this requirement. Zhang explains that lack of interest in writing and lack of relevant information to write are primary reasons for students not knowing what to write (Zhang, 2016). This indicates that without sufficient input of ideas, students are more likely to fall into the predicament of nothing being said. Therefore, supplementary materials could support students' writing and could make a positive influence on students' willingness (or ability) to express their ideas in writing.

\subsection{Personal stance}

According to the definition of $\mathrm{CR}$, it is reasonable to require readers to have their own ideas when reading. Also, Clegg believes (Clegg, 1988: 43) that Critical reading is an active reading and thinking process in which the reader distinguish between truth and distortion, information and propaganda, public policy and personal prejudice. With the regard of this, it is reasonable to encourage readers to develop their own stable meaning from texts, which is consistent with the aims of CR. In the context of this study, students with the access to supplementary materials tended to develop different views of euthanasia and were able to give reasons to support them (instead of merely following the writer's view) and it seems that they developed a better understanding of the topic as a whole. It may be generally concluded that the more reading students read, the more comprehensive understanding of an issue a learner possesses, and the more stable the views they hold.

\subsection{Personal connections}

The reason for readers to make connections between texts and themselves is that they may develop an authentic feeling on a topic if it is closely related to them and their experience of the world. The findings here show that with supplementary materials, students tend to express a stronger personal connection to the text. Scholars such as David Bleich support this subjective reader-response theory, stating that response statements must be negotiable into knowledge about reading experiences, which are confined largely to comments about the reader's memories, interests, and personal experience (Bleich, 1978:309). In this research, students in the experimental group were better equipped to make connections with their personal feelings and experience than those in the control group, which means that readers could make personal connections to respond to the text.

\subsection{Social awareness}

When CR is taught in real-classes, it should also look beyond the class towards ways in which practice could be carried out at the social level, which is also the aim of CR. Wallace who gives an explanation of CR from the view of society, indicates that a CR approach addresses social and political issues and is committed to the pursuit of social justice (Wallace, 2003: 101). Paulo Freire, a leader in critical pedagogy, highlights the importance of education for social justice in his book, where he gives the definition of "reading the world" to encourage students to unveil appearances designed to protect injustice so that equality and democracy could be achieved (Freire, 1972: 25). With regard to this, consciousness on a social level should be considered as an important criterion of CR ability. In addition, supplementary materials should provide students with opportunities to see themselves, allowing them to see the bigger, broader world outside of themselves (Sailor, Martinez, \& Villarreal, 2013) so that they may visualize themselves as productive members of society and make contributions to it. The result of this research was in accordance with those theories, since the majority of the experimental group raised their ideas and extended from the text itself to the rationality of using in social context, such as the affordable cost of euthanasia. In addition, the awareness of social justice precipitates consideration of themes related to social improvement, such as market supervision, legislative perfection and professional ethics. Students are more active to see themselves as the member of the society, in which they perform as different roles of 
the society to think about the rational of euthanasia. The observable improvements in this aspect indicate a development in CR ability, as locating literacy in wider social and political relations in which it is embedded is a good approach for supporting CR ability (Crowther \& Lyn, 2011).

\section{IMPLICATIONS}

The result proved that students' CR ability has improved through this approach. Therefore, if teachers find the text is not sufficient for cultivating CR ability, according to the principles suggested before, they could choose proper supplementary material for recommendations to get improvements of CR ability.

This study show that supplementary materials can cultivate CR ability in ER classes, while feedback from the participants also gives some suggestions of how extensive textbooks can be promoted for the improvement of CR ability. On the one hand, textbook editors could choose some supplementary materials according to the principles, so that they could provide ample reading materials for students to develop their CR ability, even if a teacher did not have time to refer directly to every supplementary article, students could read these articles independently.

As it noted before, this research is an experiment to test whether the use of supplementary materials in ER classes is feasible in terms of developing students' CR ability. It is therefore worth consideration for future research on testing this approach on a wider range, to collect and analyze more data. In addition, further research could be conducted from teacher's perspectives, finding out their advantages and difficulties of utilizing this approach.

\section{CONCLUSION}

To sum up, to test whether supplementary materials are useful to develop this ability, this research has investigated students' writing after using supplementary materials in ER classes. The results show that students' CR abilities have made some progress with the support of these materials. First of all, students are more willing to express themselves. Secondly, they are more likely to give their own stance, instead of receiving writer's opinion without their own thinking. Thirdly, they could make connections with their personal experience. Lastly, their social awareness has also been improved a lot, which is consistent with the aim of CR. Furthermore, this research gives implications for students and teachers who want to cultivate students' CR ability and what textbook designers could do to provide support.

\section{REFERENCES}

[1] Bleich, D. (1978). Subjective criticism. Baltimore. London: Johns Hopkins University Press.

[2] Clegg, C.s. (1988). Critical reading and writing across the disciplines. NY: Holt, Rinehart and Winston, Inc.

[3] Crowther, Jim. \& Tett, Lyn. (2011). Critical and Social Literacy Practices from the Scottish Adult Literacy Experience: Resisting Deficit Approaches to Learning. Literacy, 45(3): 134-140.

[4] Cai J. G. (2020) English major's objectives: challenge and change -- a study of English Major Teaching Guidelines. Journal of Northeast Normal University (Philosophy and Social Sciences):1-10[2020-08-24].

[5] Freire, P. (1972) Pedagogy of the oppressed (Penguin education). Harmondsworth: Penguin Books.

[6] Heffernan, L. \& Lewison, M. (2003). Social narrative writing: $(\mathrm{Re})$ constructing kid culture in the writer's workshop. Language Arts, 80(6), 435-443.

[7] Heffernan, L. \& Lewison, M. (2005). What's lunch got to do with it? Critical literacy and the discourse of the lunchroom. Language Arts, 83(2), 107-117.

[8] Hu, G. \& Mckay, SL. (2014). Multilingualism as portrayed in a Chinese English Textbook. In Conteh J, Meier G. (eds) The multilingual Turn in language education: Opportunities and Challenges. Clevedon: Multilingual Matters, 64-88.

[9] Hu, M. \&Nation, P. (2000). Unknown vocabulary density and reading comprehension. Reading in a foreign language, 13 (1): 403-30.

[10] Huang, Y. S. English major curriculum must be reformed thoroughly: on the absence of critical thinking. Foreign Language World, 2010(1):11-16.

[11] Jiang, J. (2013). Critical Thinking in General Education in China. International Journal of Chinese Education, 2(1), 108-134. 
[12] Kamler. B. (1999) The writing workshop as a space for relocating the personal. In B. Doecke (Ed.) Responding to studnets' writing: Continuing conservation (PP. 287-304). Norwood, SA: AATE (The Australian Association for the Teaching of English).

[13] Pirozzi, R. (2003) Critcal thinking, critical reading (2nd ed.). New York: Longman.

[14] Renandya, W., Hu, G., \& Xiang, Y. (2015) Extensive Reading Coursebooks in China. RELC Journal, 46(3): 255-273.

[15] Sailors, M., Martinez, M., \& Villarreal, L. (2013) Teacher Authored Supplementary Reading Materials in South Africa. Bookbird, 51(4): 35-46.

[16] Tomlinson B. (2012) Materials development for language learning and teaching. Language teaching, 45(2): 143-79.

[17] Twining, J. E. (1985) Reading and thinking: A process approach. NY: Holt, Rinehart and Winston.

[18] Wallace, C. (2003) Critical reading in language education. Basingstoke: Palgrave Macmillan.

[19] Wang, Jianna. (2018) A Review and Reflection on the Research of Critical Reading Mode for English Majors. Journal of North China University of Technology, 18(1):113-118.

[20] Zhang, Lili (2016) An Empirical Study on the Reform of EFL Writing Teaching. China Financial and Economic Press. 